\title{
Temperature Calculations in the Coastal Modeling System
}

by Honghai Li and Mitchell E. Brown

PURPOSE: This Coastal and Hydraulics Engineering Technical Note (CHETN) describes procedures to calculate temperature change within the Coastal Modeling System (CMS) operated in the Surface-water Modeling System (SMS), version 12.1 (Aquaveo 2010). The defined procedures are demonstrated in an application of temperature modeling in the Corrotoman River, Virginia.

INTRODUCTION: Water temperature is an important physical property influencing environmental conditions in aquatic systems. Its value changes with atmospheric conditions, typically ranging from close to $0{ }^{\circ} \mathrm{C}$ in the polar regions to more than $30{ }^{\circ} \mathrm{C}$ in tropical regions. In coastal zones and estuaries, both temporal and spatial variations in water temperature are also controlled by changes in circulation, tide, wind, and freshwater inflows. These changes in temperature can have major effects on water density and water stratification, which can change ocean mixing and modify circulation patterns. Dynamic behavior of suspended sediment can be controlled by the density-driven flow and mixing. Temperature can alter the water physical environment that impacts marine organisms with the change of water turbidity in coastal and estuarine systems. Water quality and ecological models often require input of water temperature and salinity information from a hydrodynamic model.

COASTAL MODELING SYSTEM (CMS): The CMS calculates water levels, currents, and waves through the coupling between a hydrodynamic model (CMS-Flow) and a wave model (CMS-Wave). These two models can be coupled to simulate sediment transport, morphology change, and salinity transport (Lin et al. 2008; Sanchez et al. 2014; Li et al. 2012).

CMS-Flow is a two-dimensional (2D), finite-volume model that solves the mass conservation and momentum equations of shallow water motion. CMS-Flow is forced by water surface elevation (WSE) (e.g., from tide) and river discharge at model boundaries, wave radiation stress, and wind forcing over a model computational domain. Physical processes calculated by CMS-Flow include wave-current interaction, sediment transport, morphology change, and salinity transport. CMS-Wave is a 2D, quasi-steady spectral wave transformation model. The model contains theoretically derived approximations of wave diffraction, reflection, and wavecurrent interactions for wave simulations at coastal inlets with jetties and breakwaters.

TEMPERATURE CALCULATIONS IN CMS: The CMS calculates the temperature field based on the following $2 \mathrm{D}$ heat transfer equation:

$$
\frac{\partial(T d)}{\partial t}+\frac{\partial\left(T q_{x}\right)}{\partial x}+\frac{\partial\left(T q_{y}\right)}{\partial y}=\frac{\partial}{\partial x}\left[K_{x} d \frac{\partial T}{\partial x}\right]+\frac{\partial}{\partial y}\left[K_{y} d \frac{\partial T}{\partial y}\right]+\frac{J_{T}}{\rho c_{p}}
$$


where $T$ is the depth-averaged temperature; $d$ is the total water depth; $q_{x}$ and $q_{y}$ are the flow per unit width in the $\mathrm{x}$ and $\mathrm{y}$ directions, respectively; $K_{x}$ and $K_{y}$ are the diffusion or mixing coefficients of heat in the $\mathrm{x}$ and $\mathrm{y}$ directions, respectively; $\rho$ is the water density; $c_{p}$ is the specific heat; and $J_{T}$ is the net heat flux across water or bed surfaces into the water body.

Equation (1) represents the horizontal heat transfer (advection and diffusion) in a water body considering the heat exchanges across the water and bed surfaces as heat sources/sinks. The heat content in the water body is primarily controlled by air-water heat exchanges whereas the heat flux due to conduction and convection across the bed surface is assumed to be negligible and is not included in this calculation. In addition, heat inflow from rivers and by tidal currents also affect the temperature in the water body, which can be specified as boundary conditions. Heat flux components across the water surface, including short-wave solar radiation, long-wave atmospheric radiation, latent heat flux, and sensible heat flux, can be calculated in the CMS using the following meteorological parameters: solar radiation, cloud cover, air temperature, wind speed, and surface water temperature. The bulk formulas to evaluate the heat flux components were described by $\mathrm{Wu}$ (2008), as outlined in the following:

\section{Short Wave Solar Radiation, Jsw}

$$
J_{S W}=J_{S W, C L R}\left(1-0.65 C_{C L D}^{2}\right)\left(1-R_{S W}\right)\left(1-f_{S H D}\right)
$$

where $J_{S W, C L R}$ is the short-wave solar radiation received on a water surface during a clear (i.e., cloudless) sky $\left(\mathrm{Wm}^{-2}\right) ; C_{C L D}$ is the cloud cover fraction $(0-1.0) ; R_{S W}$ is the surface reflection

coefficient; and $f_{S H D}$ is the shading factor of vegetation and landscape near a water body. If the measurements of solar radiation are available, they may be directly applied for $J_{S W}$, and the calculations of Equation (2) may be avoided.

\section{Long Wave Atmospheric Radiation, $J_{L W}$}

$$
J_{L W}=\varepsilon_{A I R} \sigma T_{A I R}^{4}\left(1+0.17 C_{C L D}^{2}\right)\left(1-R_{L W}\right)-\varepsilon_{W T R} \sigma T_{W T R}^{4}
$$

where $\varepsilon_{A I R}$ and $\varepsilon_{W T R}$ are the emissivities of air and water, respectively; $T_{A I R}$ and $T_{W T R}$ are the air and water surface temperatures, respectively; $R_{L W}$ is the surface reflection coefficient of long wave radiation; and $\sigma$ is the Stephan Boltzman constant $\left(5.670 \times 10^{-8} \mathrm{~W} \mathrm{~m}^{-2} \mathrm{~K}^{-4}\right)$.

Latent Heat Flux, $J_{E}$

$$
J_{E}=f\left(U_{W N D}\right)\left(e_{A I R}-e_{S}\right)
$$

where $f\left(U_{W N D}\right)$ is a function of wind speed, $U_{W N D} ; e_{A I R}$ is the air vapor pressure $(\mathrm{mb})$; and $e_{S}$ is the saturation vapor pressure $(\mathrm{mb})$ at the water surface. In the CMS, $f\left(U_{W N D}\right)$ is calculated using

$$
f\left(U_{W N D}\right)=6.9+0.345 U_{W N D, 7}^{2}
$$


where $U_{W N D, 7}^{2}$ is the wind speed measured at 7 meters $(\mathrm{m})$ level above the water surface (Edinger et al. 1974).

\section{Sensible Heat Flux, Js}

$$
J_{S}=C_{B} f\left(U_{W N D}\right)\left(T_{A I R}-T_{W T R}\right)
$$

where $C_{B}$ is the Bowen coefficient $\left(0.62 \mathrm{mb} \mathrm{K}^{-1}\right)$.

Therefore, the total heat flux, $J_{T}$, in Equation (1) can be obtained by

$$
J_{T}=J_{S W}+J_{L W}+J_{E}+J_{S}
$$

MODEL ASSUMPTIONS: CMS-Flow is presently capable of 2D temperature computations in the implicit solver. The simulation of temperature normally requires a three-dimensional solution due to the presence of vertical temperature gradients that can influence the flow significantly. It is therefore important to understand the limitations of $2 \mathrm{D}$ temperature simulations and apply them only when the assumptions inherent in 2D simulations are valid. Typically, 2D temperature simulations are valid when the temperature is well mixed over the water column. These conditions are usually met for shallow bays with open exchanges to the ocean or gulf and strong tidal signals and sufficient wind energy to provide the vertical mixing. Also, the assumption of sufficient energy to mix over the water column is valid under storm conditions, even for deeper water bodies. Finally, when the exchange with the open sea is restricted by an inlet, the tidal range is an important indicator of vertical mixing conditions. For low tide ranges, significant vertical stratification can occur, even in shallow bays and estuaries, especially when the winds are calm. Pritchard (1955) and Cameron and Pritchard (1963) have classified estuaries using stratification and freshwater inflow as the governing criteria, and these classifications can be used for guidance in applying the 2D simulations.

TEMPERATURE MODELING IN CORROTOMAN RIVER, VIRGINIA: In this section, temperature modeling is described to demonstrate the CMS capability in the Corrotoman River, Virginia. The temperature calculations are validated against measurements at two monitoring stations.

Background. The Corrotoman River is a small tributary of the Rappahannock River in the coastal plain of Virginia. The Y-shaped river has two branches, the western and the eastern branch, and it joins the Rappahannock River before flowing into the Chesapeake Bay (Figure 1). Freshwater discharges into the Corrotoman River come from a few small creeks and the annual flow rate is very small. The river has an average water depth of $1.7 \mathrm{~m}$ with a mean tidal range of $0.35 \mathrm{~m}$. The hydrodynamics of the Corrotoman River is predominated by tidal process with occasional passages of meteorological events. Tide and wind provide sufficient energy to mix water vertically in the shallow river. Observations by the Virginia Estuarine and Coastal Observing System indicate that depth-averaged circulation and temperature simulations are applicable to the system as the temperature is well mixed over the water column (http://web2.vims.edu/vecos). 


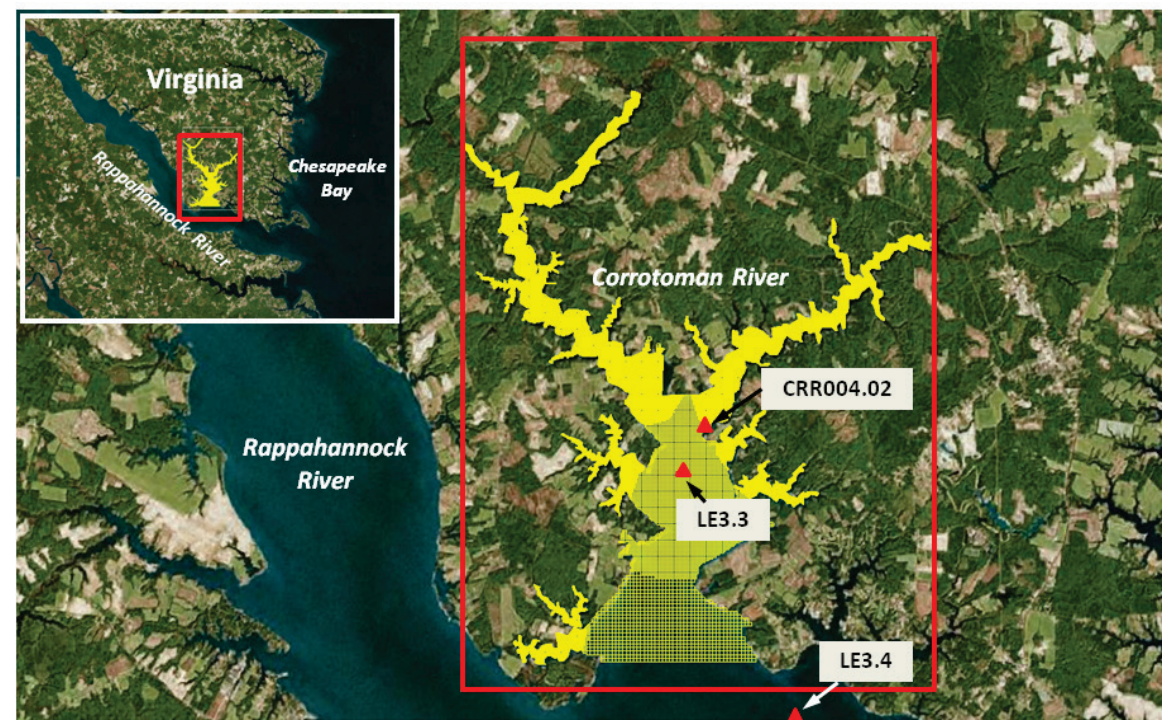

Figure 1. CMS domain, quadtree grid, and bathymetry of Corrotoman River, Virginia. Triangles indicate the survey station locations.

In application of the CMS to the Corrotoman River, a quadtree grid system was developed to discretize the computational domain, which covers approximately 13-16 kilometers from the river mouth to the upstream of the western and the eastern branch. The downstream boundary of the domain reaches to the $7 \mathrm{~m}$ depth. Figure 1 shows the quadtree grid and bathymetric features. There are 82,000 ocean cells, and the cell size ranges from $20 \mathrm{~m}$ in the upstream to $80 \mathrm{~m}$ in the downstream of the river, which permits resolution of the complicated shoreline and narrow portions of the river. The implicit solver of the CMS, with a large time-step of 10 minutes, was employed for simulations.

The temperature data used in the study were downloaded from the Virginia Estuarine and Coastal Observing System (VECOS) (http://web2.vims.edu/vecos/). Two sampling stations are located in the Corrotoman River and one near the river mouth (Figure 1). Continuous measurements of temperature were conducted at CRR004.02 with an interval of 15 minutes, and long-term samples were measured at LE3.3 and LE3.4 with an interval of 3-5 weeks. The temperature data inside the river domain (CRR004.02 and LE3.3) were used to validate the CMS temperature calculations; data near the river mouth (LE3.4) provided boundary temperature conditions along with the WSE. The simulation period was from 11 October to 9 November 2009. Based on the long-term temperature measurements at LE3.3 and LE3.4, a constant initial temperature value was specified for the entire CMS domain.

CMS-Flow was driven by time-dependent WSE at the open boundary, wind speed and direction, and other atmospheric data (solar radiation, air temperature, cloud cover) over the surface boundary. WSE forcing was downloaded from a National Oceanic and Atmospheric Administration (NOAA) tidal gage at Windmill Point, VA (\#8636580). Wind, air temperature, and cloud cover were obtained from National Centers for Environmental Information (http://www.ncdc.noaa.gov/customer-support/online-store) and solar radiation data from National Solar Radiation Data Base (http://rredc.nrel.gov/solar/old_data/nsrdb/) at Langley AFB station. 
CMS setup for temperature calculation. The CMS hydrodynamic input files for the Corrotoman River were prepared using the SMS (Figure 2). Instructions for setting up a CMS temperature simulation are described below.

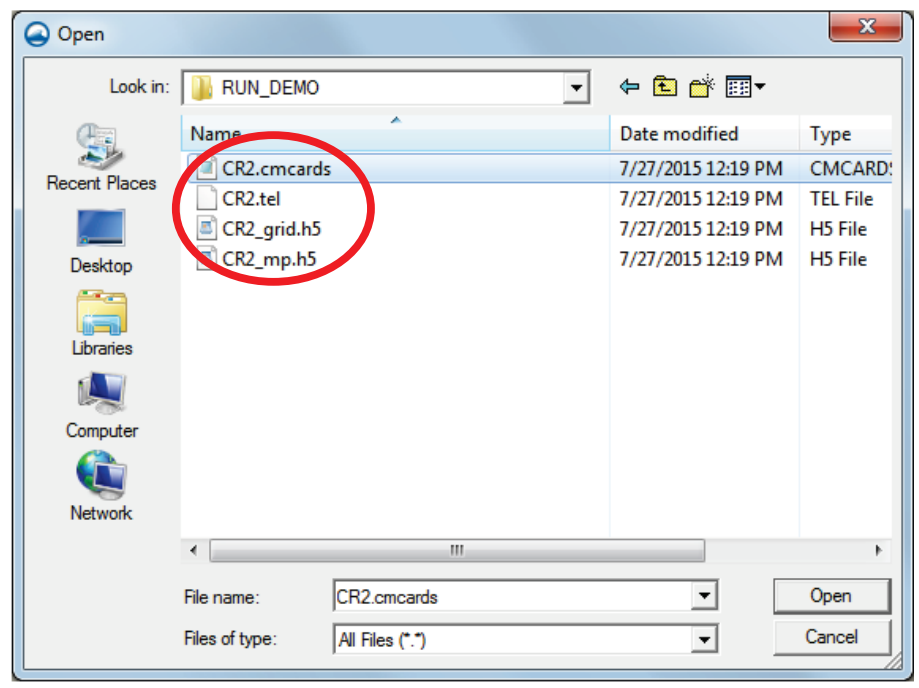

Figure 2. Files for the CMS-Flow temperature simulation.

After opening "CR2.cmcards" in SMS 12.1, right-click the simulation name under "CMS-Flow Simulations" in the SMS Data Tree and choose Model Control, click on the Salinity/Temperature tab, and check the box next to Calculate temperature. A default time-step equal to the hydrodynamic time-step will be specified. In this case, 600 seconds was used for the temperature calculation, equal to the 10-minute hydrodynamic time-step. Atmospheric parameters that cover the computational domain must be specified. That step is covered in the Air-Water interface section.

1. Temperature initial condition. Because of the large spatial variability of temperature in a coastal system, long spin-up periods are usually required, which could range from a few days to weeks for a simulation to reach to the present temperature distribution. To shorten the spin-up time, an initial temperature field should be specified based on available information. There are two options to assign the initial temperature condition in CMS-Flow:

2. A global initial temperature. Specify a constant initial value for the entire model domain. The temperature value can be specified by choosing Constant Water Temperature under the Initial condition section (Figure 3 ) and entering a value under Water properties. If this option is applied, it is best to define an average representative temperature for the entire domain. 


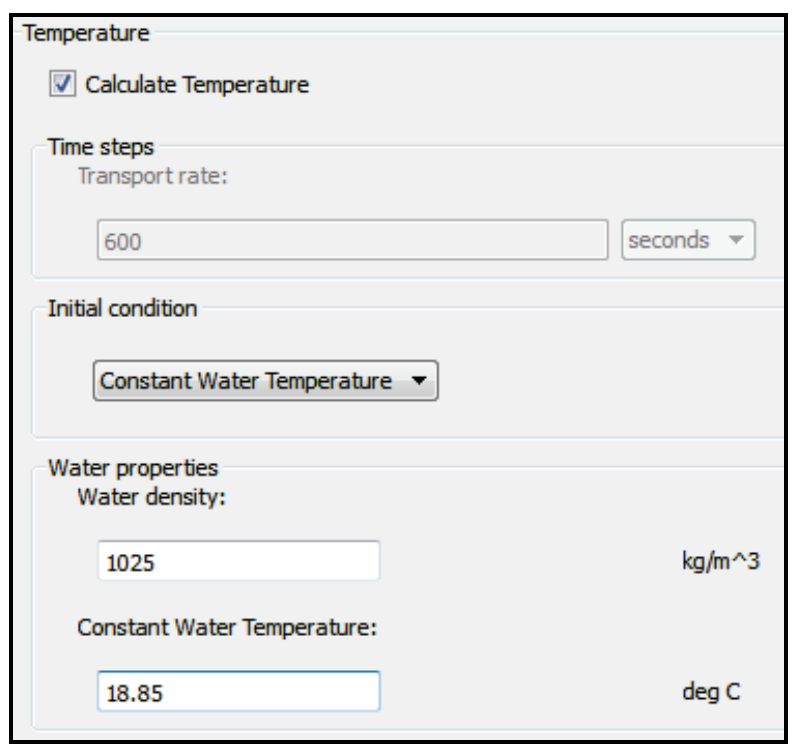

Figure 3. Temperature dialog showing options for the Constant Water Temperature initial condition.

3. Spatially varying initial temperature. Generate a spatially varying initial temperature field by choosing Spatially varied toggle under the Initial condition section (Figure 4a) and then the Select button. Clicking the Create Dataset button in the resulting dialog will bring up the Data Calculator where a value can be assigned in the calculator entry box and then enter an output dataset name such as "Initial temperature, C." The Compute button must be clicked before proceeding out of the dialog. Close all the way out of the dialogs by clicking Done to close the data calculator; then click $O K$ twice to close the CMS-FLOW Model Control window. A dataset with the name provided in the calculator will appear in the CMS-Flow data tree, as shown in Figure 5. Highlight the dataset to specify different temperature values in the CMS domain in the same way to modify other datasets such as "Manning's $n$." For an existing dataset, click the Select button under the Spatially varied toggle and then select the existing dataset for the initial temperature (Figures 4 and 5).

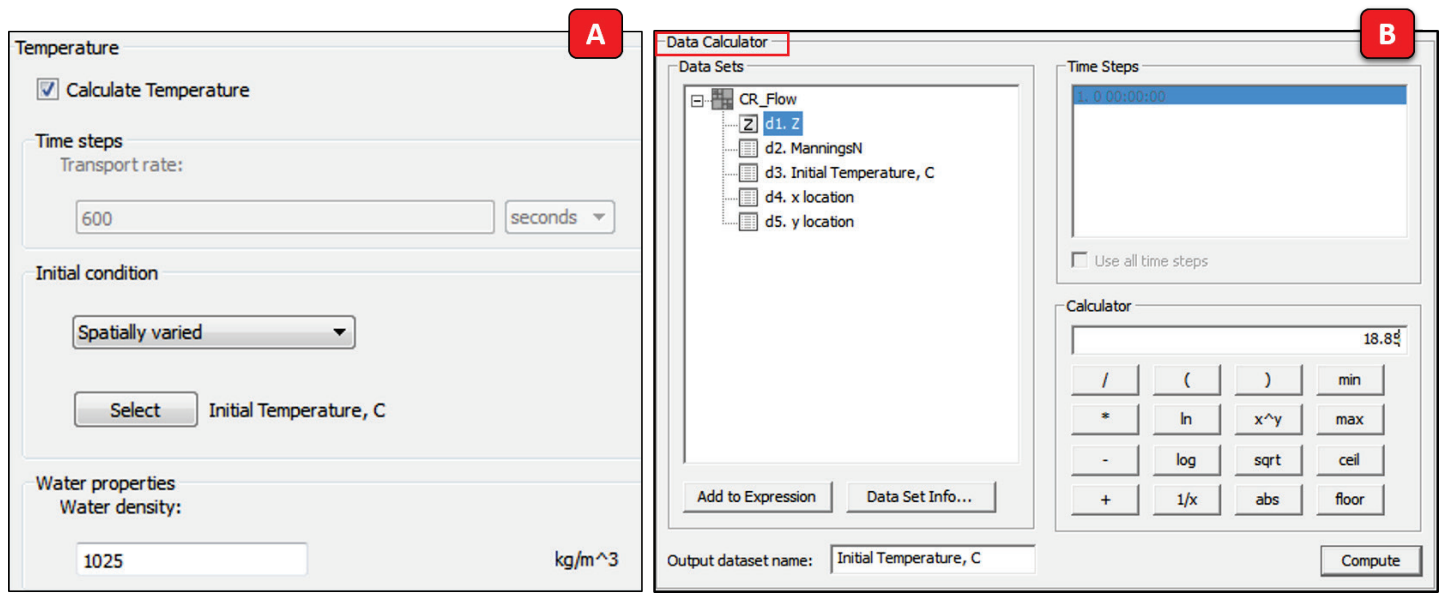

Figure 4. a) Temperature dialog for the Spatially varied initial condition. b) The Data Calculator for specifying the value and the dataset name of the initial condition. 


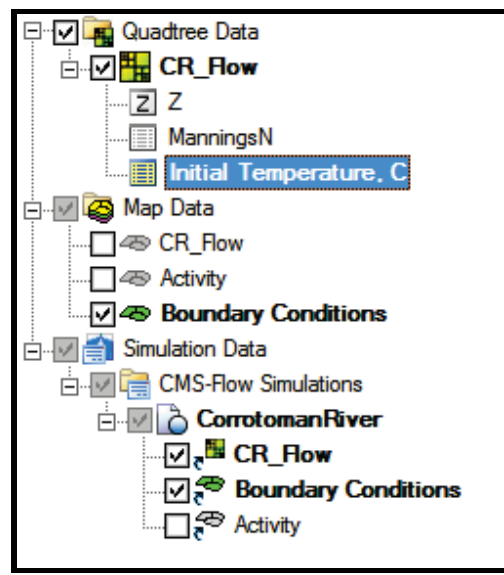

Figure 5. SMS data tree for the newly created dataset.

4. Based on the survey data, temperature only varies by $0.5-1.0^{\circ} \mathrm{C}$ from near the mouth to the upstream of the river during the simulation period. Therefore, the initial temperature was obtained by the temporal interpolation of the measurements at LE3.4, and a constant value of $18.85^{\circ} \mathrm{C}$ was assigned for the Corrotoman River system.

5. Temperature boundary conditions. To calculate temperature transport, temperature values at CMS-Flow boundaries must be specified. As described in Li et al. (2012), there are two boundary types in the CMS for salinity calculations: WSE boundaries (WSEforcing boundary) (Figure 6) and freshwater inflow boundaries (Flow rate-forcing boundary). For temperature calculations, heat transfer at the air-water interface (surface boundary) needs to be calculated.

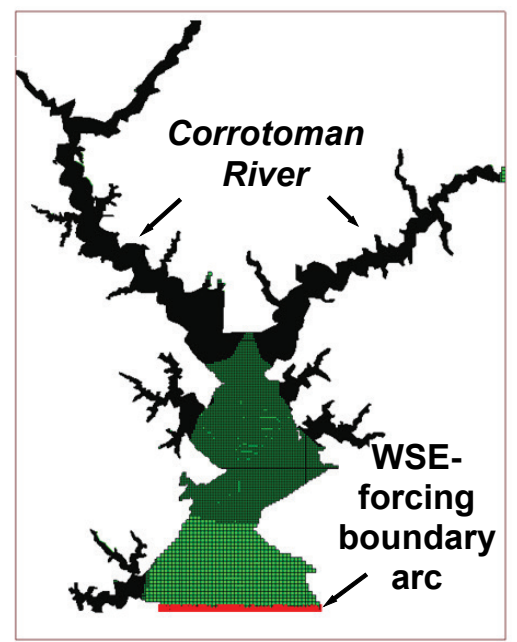

Figure 6. Temperature boundary types in the CMS. 
i) WSE-forcing boundary. In the SMS Data Tree, select the Boundary Conditions coverage in the Map Module and use the Select Feature Arc tool, $\vec{\Gamma} \mid$, to left-click and select the WSE boundary arc (Figure 6). After selecting the arc, right-click and choose the Assign Boundary Conditions option (see Figure 7a for the Arc Boundary Condition dialog). A time series of temperature can be assigned along the WSEforcing boundary by checking the Define Temperature Curve box, then clicking the Curve undefined button at the bottom center of the dialog.

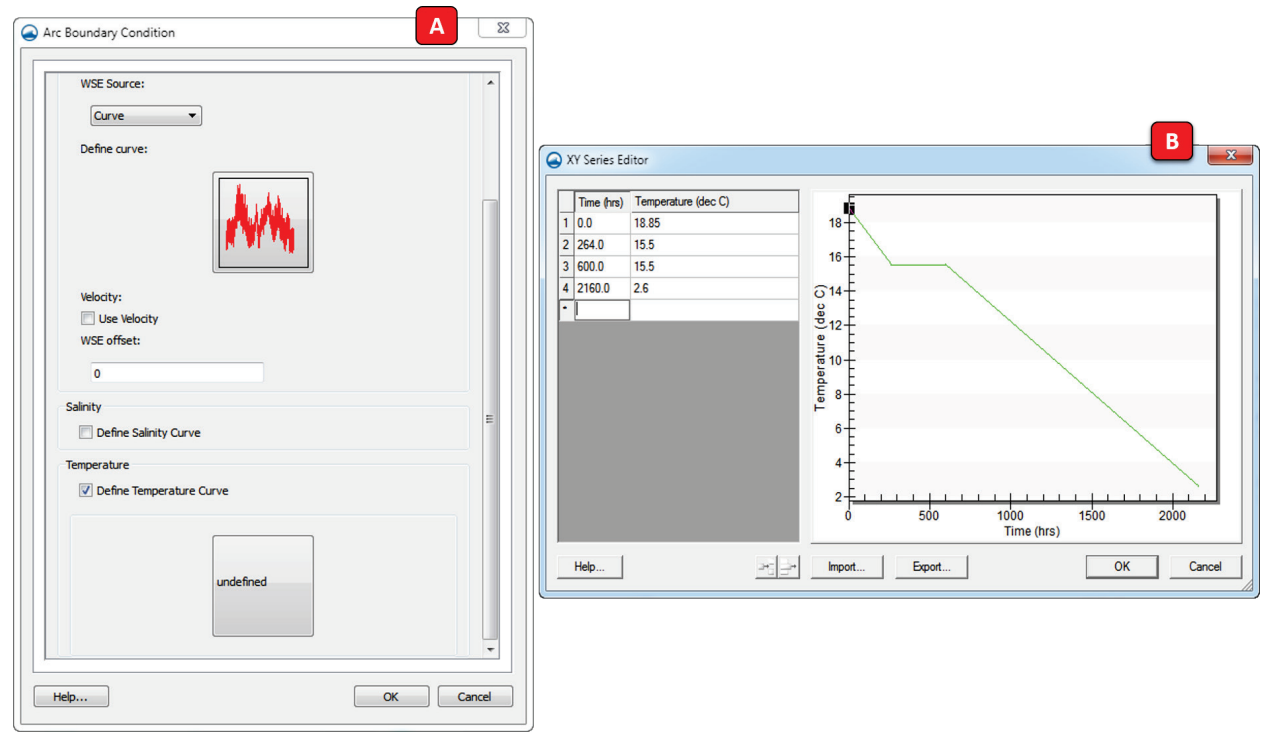

Figure 7. a) Image of the Arc Boundary Condition dialog. b) Image of the temperature boundary input window.

6. The time series is specified either by clicking the Import button to read a temperature boundary input file in xys format (Aquaveo 2010), by entering time and temperature values manually in two separate data columns, or by importing temperature data from an opened Excel file using Copy/Paste (Figure 7b).

7. Figure 7 shows the temperature measurements at the long-term station, LE3.4 (SeptemberDecember 2009), which were assigned to the offshore boundary with the WSE measurements at the NOAA tidal gage, Windmill Point, VA.

i) Flow rate-forcing boundary. Following the same steps as specifying WSE-forcing boundary, temperature values at freshwater inflow boundaries can be assigned together with flow specifications.

ii) Air-water interface. Equations (2) through (6) are used to calculate heat fluxes at the air-water interface. Air temperature, dew point temperature, cloud cover, and solar radiation are obtained from the NOAA weather station, Langley Air Force Base, Virginia, and must be specified in the Temperature section of the Salinity/Temperature Model Control interface as shown in Figure 8. 


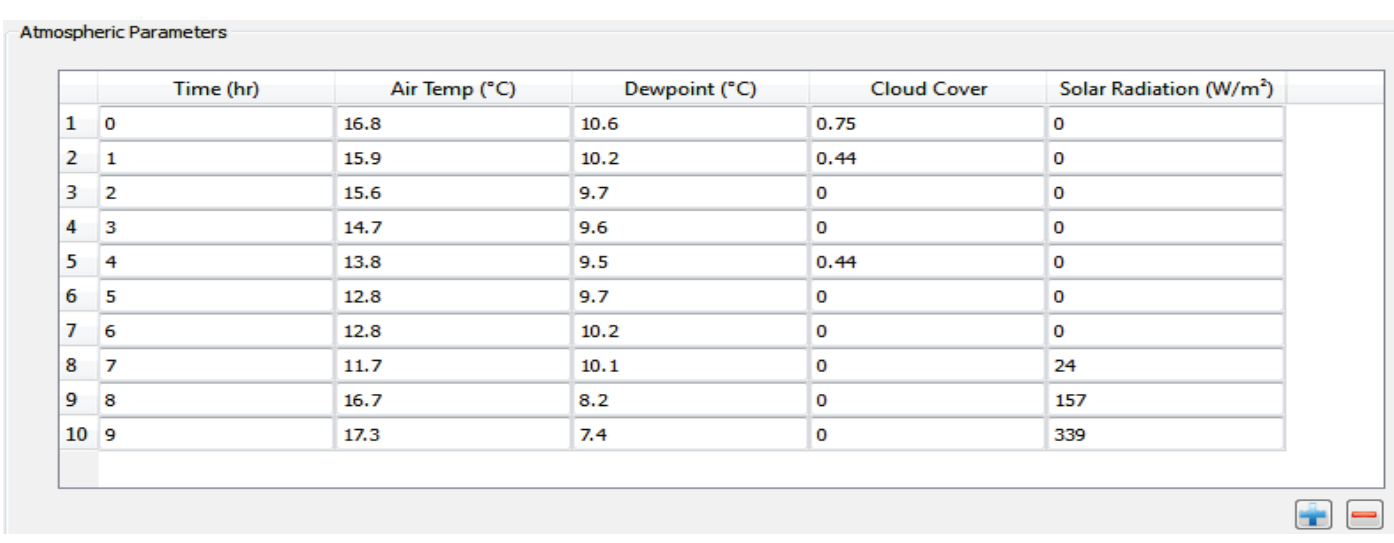

Figure 8. Atmospheric Parameters dialog in Temperature Model Control interface.

SIMULATION RESULTS: For the demonstration in the Corrotoman River, the CMS-Flow simulation was conducted for a 30-day period (11 October-9 November 2009). Depth-averaged current and temperature fields in the system were retrieved from four snapshots of the CMS results at a 6-hour interval on 21 October 2009, corresponding to the ebb and flood currents, respectively (Figure 9).

Figure 9 shows that peak currents occur near the river mouth with a current speed of 15 centimeters per second $(\mathrm{cm} / \mathrm{sec})$ during the ebb and flood periods. Daily variations in temperature are clearly displayed in the figure, which are more significant in extreme shallow (marsh) areas from 10 to $20^{\circ} \mathrm{C}$ and less than $1{ }^{\circ} \mathrm{C}$ in the deep portions of the river.

Model temperature calculations in the system were checked using measurements at stations CRR004.02 and LE3.3 in Figure 10. Stations CRR004.02 and LE3.3 have water depths of 1.8 and $6.6 \mathrm{~m}$, respectively. Calculated temperature at LE3.3 shows smaller temporal variations of less than $5{ }^{\circ} \mathrm{C}$ and at CRR004.02 a larger variability of $6-7^{\circ} \mathrm{C}$ during this 30-day simulation period. Controlled by meteorological conditions, the temperature at the shallow site also shows large diurnal changes of more than $2{ }^{\circ} \mathrm{C}$.

Statistical parameters were calculated for the evaluation of the CMS performance at CRR004.02. The correlation coefficients and the root mean square error (RMSE) are 0.866 and $0.523{ }^{\circ} \mathrm{C}$, respectively, which indicate a good agreement between the calculations and the measurements at this site. The sensitivity tests reveal that temperature variations in the system are primarily controlled by meteorological conditions, and ocean processes, tides in this case, also play a big role, especially in deep areas.

The CMS simulations represent the temperature variations in the Corrotoman River to an accuracy level useful for understanding general temperature patterns in the river. Based on the study results, further improvement can be achieved through increasing knowledge of the temporal variation and spatial distribution of temperature and the ocean and atmospheric processes in the river/estuarine system (e.g., by adding a term to account for the flux of heat into and from the sediment bed). 

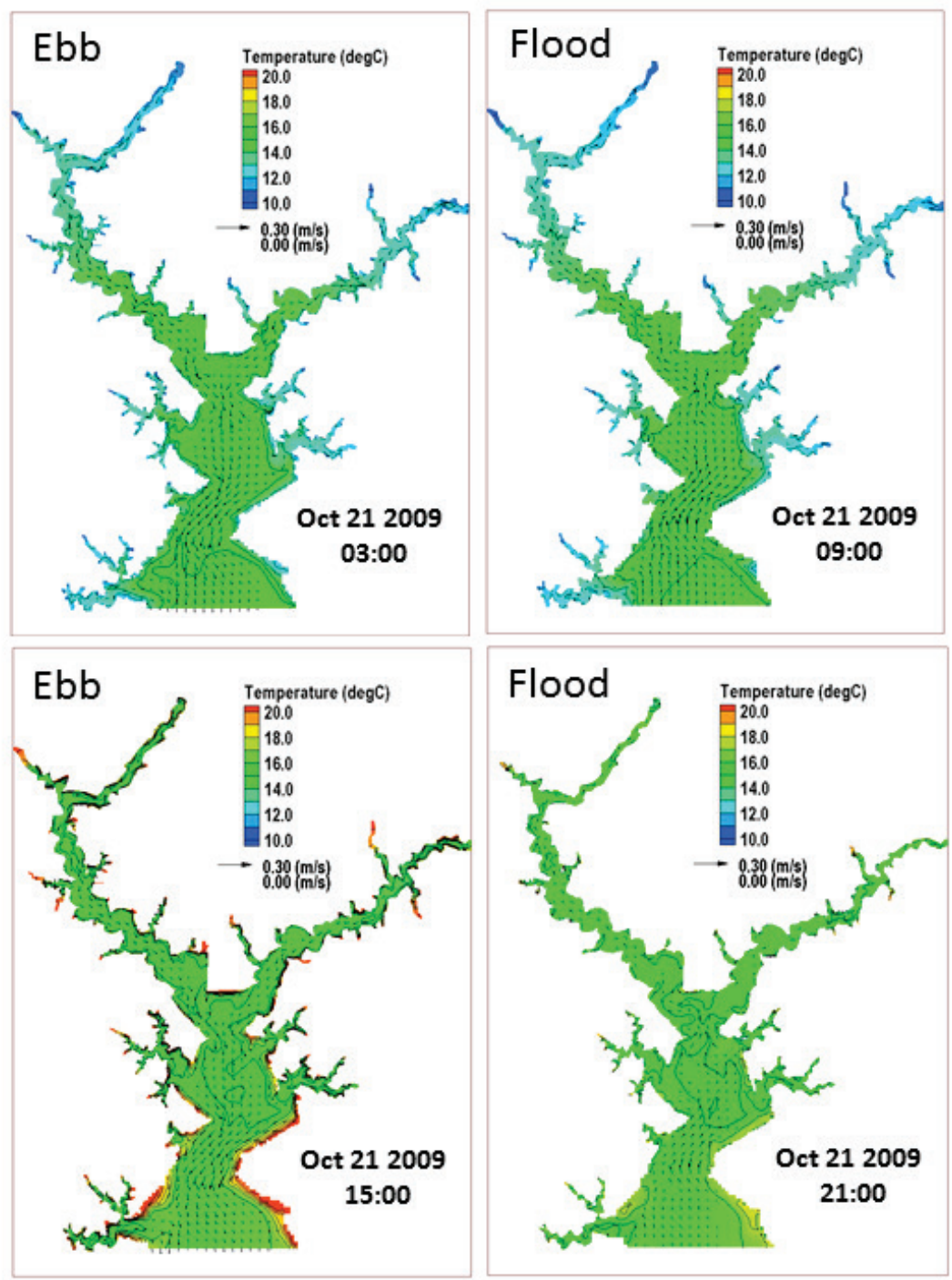

Figure 9. Temperature and current distributions on 21 October 2009 at 03:00, 09:00, 15:00, and 21:00 EST.

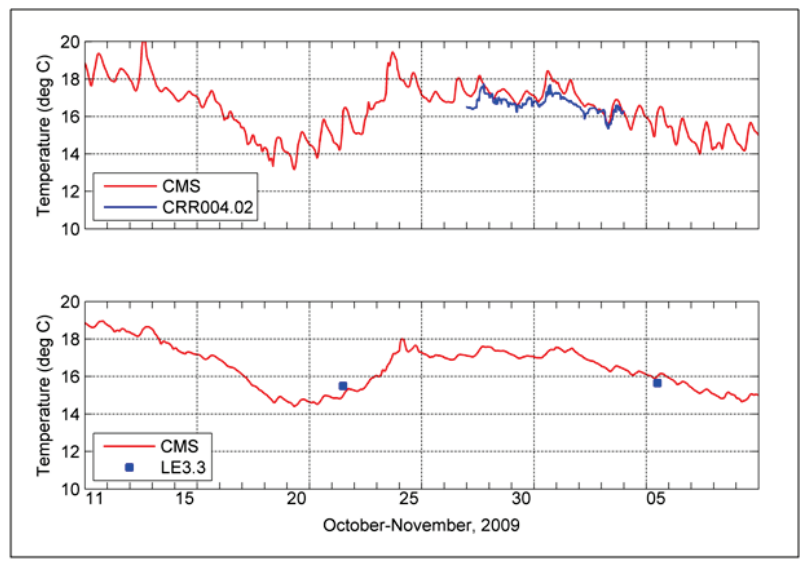

Figure 10. Calculated and measured temperature at stations CRR004.02 and LE3.3 for October-November 2009. 
CONCLUSIONS: The Coastal Modeling System's capability in computing the depth-averaged temperature calculation in the Corrotoman River was demonstrated in this technical note. The example shows that the procedures to set up a CMS temperature calculation are straightforward and user friendly. This estuarine application provides a validation example for the CMS and satisfactorily reproduces the temporal variations and spatial distributions of temperature. Because the CMS does not simulate the ice freezing/melting process, the temperature calculation is not applicable to ice covering regions. Further improvement to the CMS can be made as different bulk formulas are introduced into the model to calculate the heat flux components for applications in coastal, estuarine, or riverine environments.

ADDITIONAL INFORMATION: This CHETN was prepared and funded under the Coastal Inlet Research Program (CIRP) and was written by Dr. Honghai Li (Honghai.Li@usace.army.mil, voice: 601-634-2840; fax: 601-634-3080) of the U.S. Army Engineer Research and Development Center (ERDC), Coastal and Hydraulics Laboratory (CHL). The CIRP Program Manager, Dr. Julie D. Rosati (Julie.D.Rosati@usace.army.mil), and Dr. Weiming Wu, professor at Clarkson University(wwu@clarkson.edu ), reviewed this CHETN. Files for the example may be obtained by contacting the author. This CHETN should be cited as follows:

Li, H., and M. E. Brown. 2017. Temperature calculations in the Coastal Modeling System. ERDC/CHL CHETN-IV-110. Vicksburg, MS: U.S. Army Engineer Research and Development Center. http://dx.doi.org/10.21079/11681/21666

\section{REFERENCES}

Aquaveo. 2010. SMS: XY Series Files (*.xys). http://www.xmswiki.com/xms/SMS:XY Series_Files_(*.xys).

Cameron, W. M., and D. W. Pritchard. 1963. Estuaries. In The sea, vol. 2, ed. M. N. Hill, 306-324. New York: John Wiley and Sons.

Edinger, J. E., D. K. Brady, and J. C. Greyer. 1974. Heat exchange and transport in the environment. Rep. No. 14, Cooling Water Res. Project (RP-49). Palo Alto, CA: Electric Power Research Institute.

Li, H., C. W. Reed, and M. E. Brown. 2012. Salinity calculations in the Coastal Modeling System. ERDC/CHL CHETN-IV-80. Vicksburg, MS: U.S. Army Engineer Research and Development Center. http://acwc.sdp.sirsi.net/client/search/asset/1005920

Lin, L., Z. Demirbilek, H. Mase, J. Zheng, and F. Yamada. 2008. CMS-Wave: A nearshore spectral wave processes model for coastal inlets and navigation projects. ERDC/CHL-TR-08-13. Vicksburg, MS: U.S. Army Engineer Research and Development Center.

Pritchard, D. W. 1955. Estuarine circulation patterns. Proceedings of the American Society of Civil Engineers 81(717): 1-11.

Sánchez, A., W. Wu, H. Li, M. E. Brown, C. W. Reed, J. D. Rosati, and Z. Demirbilek. 2014. Coastal Modeling System: Mathematical formulations and numerical methods. ERDC/CHL-TR-14-2. Vicksburg, MS: U.S. Army Engineer Research and Development Center.

Wu, W. 2008. Computational river dynamics. London: Taylor \& Francis.

NOTE: The contents of this technical note are not to be used for advertising, publication, or promotional purposes. Citation of trade names does not constitute an official endorsement or approval of the use of such products. 